\title{
FRCM composites mesh anchorage - a way to increase strengthening effectiveness
}

\author{
Filip Grzymski ${ }^{1}$, Dorota Marcinczak $^{1}$, Tomasz Trapko ${ }^{1, *}$ and Michat Musiał ${ }^{1}$ \\ ${ }^{1}$ Wrocław University of Science and Technology, Faculty of Civil Engineering, Pl. Grunwaldzki 11, \\ 50-377 Wroclaw, Poland
}

\begin{abstract}
FRCM (Fabric Reinforced Cementitious Matrix) composites are the next stage of development of composite structural reinforcement after FRP (Fibre Reinforced Polymers) composites. The main element that distinguishes the newer FRCM system is the matrix of the composite mineral matrix instead of epoxy resin. Changes in the structure of the composite, resulting from the change of the matrix, have a big impact on its work mechanisms. This paper discusses FRCM composites and shows its effectiveness in reinforced concrete elements strengthening. The basic information on FRCM mesh fibres material differences and composite failure modes are given. Current trends and directions of composite structural strengthening and the latest research in the area of increasing FRCM composite strengthening effectiveness, that are being conducted by the authors, are presented.
\end{abstract}

\section{Introduction}

The need of reinforced concrete structures strengthening can be caused by various reasons. Most often, the decrease in load-bearing capacity of the structure is related to degradation of mechanical properties of the materials, action of an aggressive environment, exposure to excessive loads and design or construction errors. The strengthening may also be necessary as a result of the planned change in the use of the structure, which may involve an increase in loads or a change in the static system. There are many well-known and often used traditional methods of reinforced concrete structures strengthening, but they have many disadvantages that in some cases prevent their use. The main ones are their large size and heavy weight, which may also have the effect of reducing the utility values of the structure.

At the beginning of the 1980s, the use of FRP (Fibre Reinforced Polymers) composites as a structural strengthening was popularized. Their properties such as high strength-toweight ratio and corrosion resistance have made them a good alternative to traditional methods of strengthening [1]. These composites are made of various types of high-strength fibres immersed in epoxy resin matrix. Despite the many undeniable advantages, the FRP composites have a major drawback related to their resistance to elevated temperatures. This phenomenon results from the strength characteristics of the epoxy resin depending on the temperature. The temperature below which it works in a solid state is known as the glass transition temperature $\left(T_{g}\right)$. Exceeding the threshold of glass transition temperature causes the matrix to enter the soft or viscous state, at which no stiffness nor 
strength of the material are shown [2]. The matrices used commonly in FRP structural strengthening have glass transition temperature of about $+50{ }^{\circ} \mathrm{C}$ [3], which is a relatively small value in the event of fire. There are many studies confirming the decrease in the effectiveness of FRP strengthening in elevated temperatures [3-5].

The solution to this problem is to change the matrix of the composite. FRCM (Fabric Reinforced Cementitious Matrix) composites use mineral mortar instead of epoxy resin. Cementitious matrix is characterised by good mechanical parameters and high temperatures resistance. Additionally, it needs less surface preparation before application and can be used on wet surfaces [6]. Due to the change of the matrix to one with a much lower penetration capacity, it was necessary to change the arrangement of the reinforcing fibres. Mechanical interlock mechanism is formed between the fibres and the matrix [1], so loosening the fibres in the form of a mesh is needed to allow the matrix to pass through the layer of fibres.

\subsection{Fibres in FRCM composites}

There are various fibres that can be used in FRCM composites and some of them are also used in FRP systems. The most frequently used fibres in combination with mineral matrix are carbon, glass and PBO ( $p$-Phenylene Benzobis Oxazole) fibres. PBO fibres are a new generation of synthetic fibres that are characterised by very high mechanical properties, even when compared to other high-strength fibres. Basic mechanical properties of typical FRCM fibres are presented in Table 1.

Table 1. Mechanical properties of the most popular fibres used in FRCM composites [7-9].

\begin{tabular}{|c|c|c|c|}
\hline \multirow{2}{*}{ Fibre Material } & Tensile strength & Young's Modulus & Maximal strain \\
\cline { 2 - 4 } & {$[\mathrm{MPa}]$} & {$[\mathbf{G P a}]$} & {$[\%]$} \\
\hline PBO & $5270-5800$ & 270 & $2,00-2,15$ \\
\hline Carbon & 4800 & 240 & 1,80 \\
\hline Glass & 2600 & 80 & 3,25 \\
\hline
\end{tabular}

PBO mesh (Fig. 1) is produced in loose pattern typical for FRCM composites. Specially designed composition of a dedicated mineral mortar provides chemical bond between the matrix and the fibres, which allows higher forces to be carried by the strengthening.

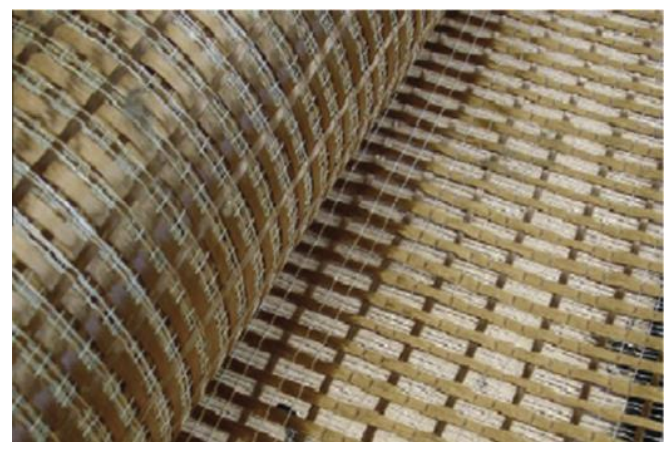

Fig. 1. $\mathrm{PBO}$ mesh [7]. 


\subsection{FRCM composite failure modes}

FRCM composites behaviour under tension is significantly different from the FRP, which work manifests itself in a linear stress-strain model. Because of lower tensile strength of mineral mortar compared to epoxy resin, the bi-linear model applies to the composites made using this type of matrix [1]. The first line of the bi-linear model represents the state prior to matrix cracking, while the second one shows the composite behaviour after the matrix is fully cracked and only the properties of the fibres affect its strength. In some cases, when the process of mortar cracking is longer, third intermediate line is observed [10]. The graphical interpretation of both models is presented in Fig. 2.

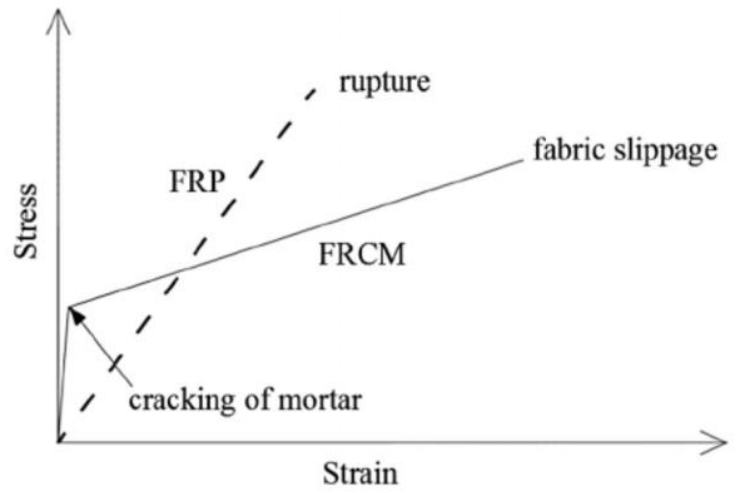

Fig. 2. Stress-strain model of FRCM and FRP under tension [1].

There are many studies regarding the mechanisms of FRCM composites behaviour and failure [6, 10-12]. The research on pure FRCM specimens tensile strength shows the difference of effectiveness of various fibres used in the composites. The PBO fibres, when compared to glass and carbon fibres, provided the highest load-bearing capacity and the strongest connection on fibre-matrix interface. The telescopic effect on the fibres that are not in a direct contact with the matrix was observed [10]. The typical failure mode observed in FRCM strengthened specimens is debonding of the composite. It occurs on the interface between the matrix and the mortar, which proves that the substrate does not have a significant impact on the composite failure [11]. Other researchers obtained similar results, but additionally a slippage of the fibres just before failure was observed [6]. When more than one layer of composite mesh is applied the debonding between compositeconcrete interface is more likely. No damage to the substrate was observed during this research [12].

It is visible that the failure of FRCM composite is not due to the strength of the fibres, but its source is the trouble with keeping the composite layers together. It leads to insufficient use of the potential of high-strength fibres such as PBO fibres, which is further intensified by the telescopic effect. The research on finding a solution to this problem is currently the most important challenge in the field of FRCM composites.

\subsection{Anchorage of FRCM mesh}

To avoid the problem with premature debonding of FRCM mesh and to increase the efficiency of FRCM reinforcements, suitable anchoring of the mesh should be used. In the tests conducted on rectangular beams strengthened with FRCM with anchorage [13] it was shown that beams with anchorage are able to transfer larger loads, and PBO fibres are more effectively used (have larger deformations) compared to beams without anchorage [14]. Despite the use of anchorage, failure due to rupture of PBO fibres was not achieved. 
Failure, as for the beams without anchorage, was due to debonding of the fibres from the matrix and development of diagonal cracks.

In the literature there is still a lack of tests on T-shaped RC beams reinforced with PBOFRCM shear strengthening with anchoring. Studies of T-beams with shear strengthening with carbon and glass fibre mesh on cement mortar [15-18] showed that the anchorage has a large contribution in the bearing capacity of the whole element, because it delays the moment of mesh debonding.

The latest own research was carried out on T-beams reinforced with shear using PBOFRCM composite materials with three types of anchorages [19]. In the tests the shear strength was found to increase by $10-27 \%$ in comparison with the unstrengthened reference beam. Thanks to the use of anchorage the strength properties of the PBO mesh can be better utilized. In the tests the maximum strains in the composite reached $8.23 \%$, which amounts to $47 \%$ of the ultimate tensile strain. For beams strengthened with the PBO-FRCM system without anchorage the maximum strains in the composite reached 3.5\%o [14], which proves the effectiveness of the strengthening.

Until the diagonal cracks appears, PBO-FRCM composites behave linearly, and the increment of deformation is very small. At the moment of exceeding the shear strength of the concrete diagonal cracks are formed and strains in the PBO stirrups suddenly increase, which means that composite begins fully cooperate in transfer of shear forces and begin to behave nonlinearly. As in the case of PBO-FRCM composites in tension, telescopic effect and slippage of the fibre were observed, which is due to inaccurate coverage of all fibre by the mortar. The debonding occurs in the fibre-mortar layer, confirming that the crucial point of this type of composite materials is bond between fibre and matrix. Figure 3 shows failure of tested beams with anchorage.

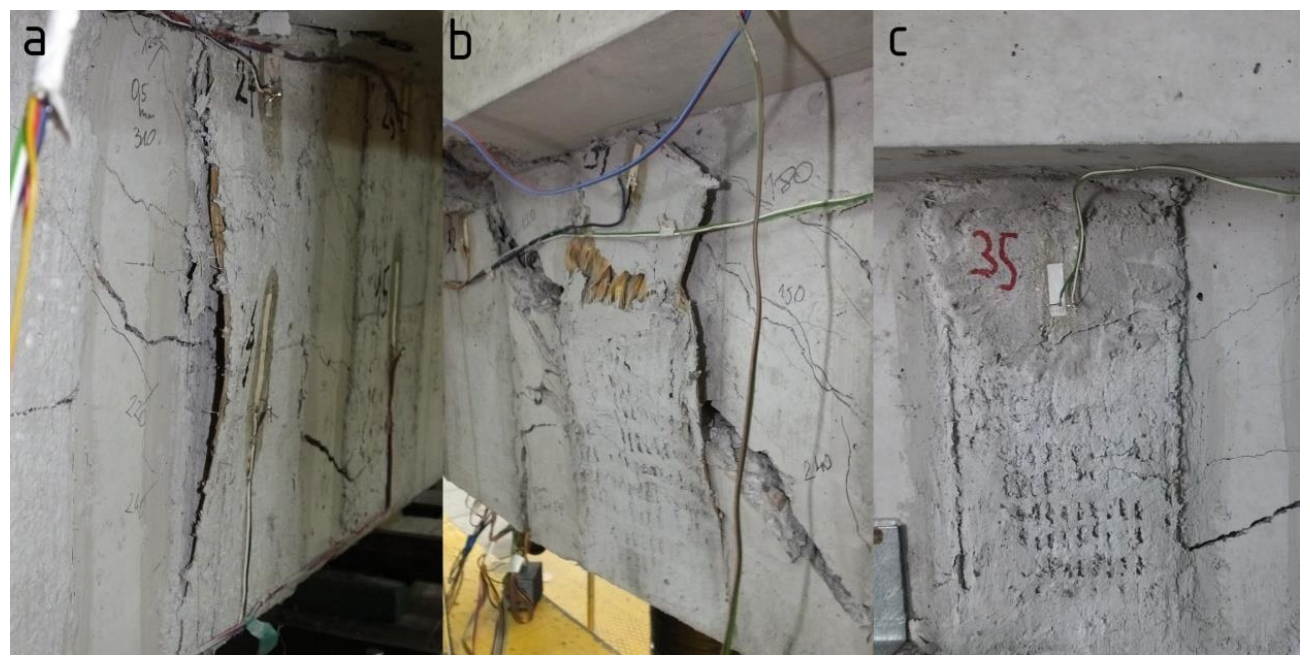

Fig. 3. Beams after failure; a) PBO debonding, b) PBO debonding and slippage, c) slippage of the fibre on the mortar layer [19].

\section{Methods}

In order to evaluate the influence of the anchorage on the performance of reinforced concrete structural elements two series of tests have been proposed. The present research conducted by the authors involve FRCM strengthened slab type elements subjected to bending and beam elements with FRCM shear strengthening. The strains 
of reinforcement steel and composite will be measured with strain gauges, to evaluate the differences between the different anchoring types. In some elements the experimental method of optic fibre strain gauge will be used.

\subsection{Slab flexural strengthening}

The series of 7 reinforced concrete slab type elements is designed to test different methods of anchoring of PBO-FRCM composite. The tests will be conducted using one-way singlespan simply supported specimens strengthened in flexure with PBO-FRCM. The dimensions of the elements used are $2000 \times 1000 \times 1500 \mathrm{~mm}$ with the span length of 1700 $\mathrm{mm}$. The reinforcement used in the elements consists of $8 \phi 10$ bars at the bottom surface and $8 \phi 8$ bars at the top. $\phi 8$ bars in the spacing of $200 \mathrm{~mm}$ are used as a secondary reinforcement. The basic information on elements and test setup geometry is presented in Fig. 4.
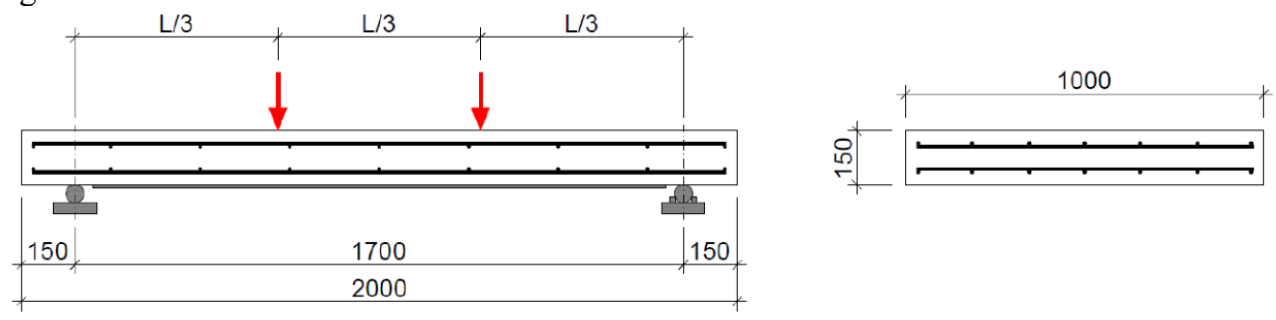

Fig. 4. Slab type element test setup.

One of 7 elements will be unstrengthened to be used as a witness sample to compare the results. The remaining 6 elements are divided into 3 groups with different types of anchorage. The first group will contain PBO-FRCM strengthening without any anchorage applied. In the second group a GFRP rebar wound with PBO mesh will be placed in the previously prepared groove at the strengthening ends. The last group will use the anchoring made of PBO cord threaded through the holes in the plate at the end of the composite. It is expected that anchored mesh of flexural strengthening will transfer greater strains without delamination or debonding compared to unanchored mesh, and thus allow to carry greater loads and reduce deflection. The strains on the secondary direction of the slab will be also measured and analysed to evaluate the slab effect in flexure.

\subsection{Beams shear strengthening}

The series of 6 reinforced concrete T-beams is designed to test different methods of strengthening with PBO-FRCM composite. The tests were carried out on T-beams with cross-sectional dimensions of $350 \times 400 \mathrm{~mm}$, web width $150 \mathrm{~mm}$ and total length of 2300 $\mathrm{mm}$. The main tensile reinforcement was selected so that there was no damage due to bending before the shear capacity was exhausted. The beams were reinforced at the bottom with 5 bars with a diameter of $20 \mathrm{~mm}$ and 2 bars with a diameter of $20 \mathrm{~mm}$ at the top. Stirrups with a diameter of $8 \mathrm{~mm}$ were made of the same type of steel. The spacing of stirrups was $250 \mathrm{~mm}$ (Fig. 5). 

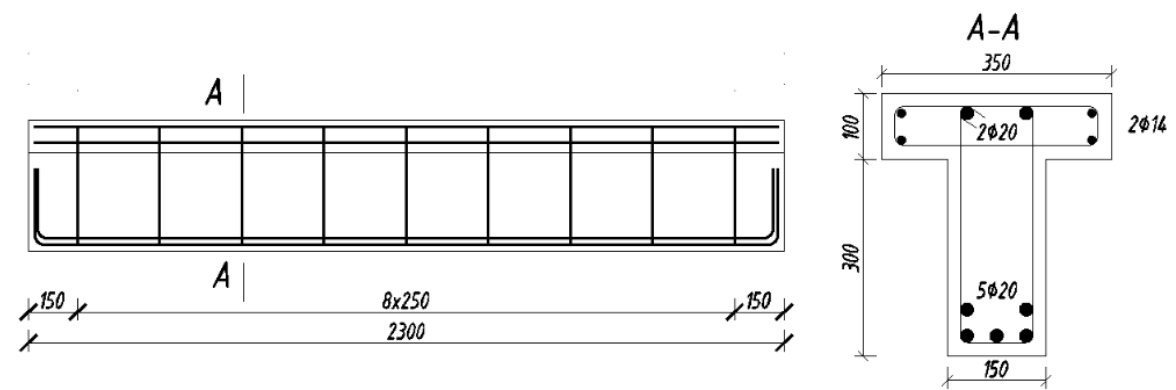

Fig. 5. Schematic of steel reinforcement and beam cross section.

Four of the beams were shear strengthened with a PBO fibre mesh bedded in mineral mortar (PBO-FRCM) and two beams were not reinforced (the reference beams). The same strengthening configuration with the same anchorage was used for each of the strengthened beams. The width of the PBO mesh strips for each beam was $150 \mathrm{~mm}$ and their spacing was $100 \mathrm{~mm}$. (Fig. 6). All strengthened beams have $20 \times 20 \mathrm{~mm}$ cuts made under the slab. When strengthening were made on the side and bottom walls of the web, the ends of the PBO strips were wound on a GFRP bar and glued in a cut under the shelf. The bar had a length equal to the length of the beam and together with the PBO strips were covered with an outer layer of mortar. The four strengthened beams were divided into 3 groups with different way of making strengthening. Beam B_P has been reinforced in a classic way, turned for a time of strengthening upside down, in order to make reinforcement easily. Beam B_P_I has been also reinforced in classic way, but before making reinforcement, the PBO mesh strips were impregnated with epoxy resin. This was to achieve a better combination of fibre in each bundle. Beams B_P_OB were reinforced under a load of $14 \mathrm{kN}$, which imitated the weight load of the ceiling. The beam remained under load from the time of reinforcement to the moment of testing.

Research is ongoing, but the first results show that there is no significant effect of reinforcing the beam under load on its shear capacity. The values of the load-bearing capacity of reinforced beams were similar. However, these are not final conclusions, because not all elements have been tested yet.
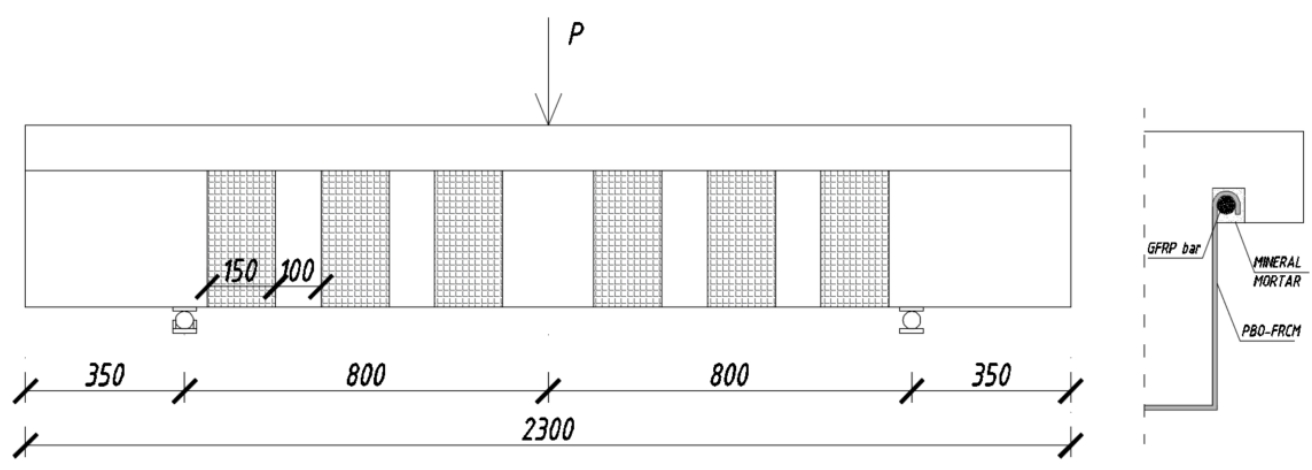

Fig. 6. Schematic of shear reinforcement of beams. 


\section{Discussion}

Composite strengthening of reinforced concrete elements is a promising method that is still being developed. The ability to use whole potential of the high-strength fibres will allow to gain even higher load capacity, and thus improve economic factors. Strengthening of RC structures using FRCM composites is increasingly the subject of scientific research and practical applications. This system is resistant to high temperatures and moist ground, easy to apply and non-toxic, making it a good alternative to the commonly used FRP composites, especially in structures exposed to high temperatures.

It should be noted, that the FRCM composites have significantly different mechanism of work than FRP composites. Mineral mortar used as a matrix is not able to provide such a good coverage of all fibers as epoxy resin. It causes slip phenomenon and telescopic effect, and a more ductile nature of the composite. The failure usually occurs as a result of debonding of the composite in mortar-fibre layer. Due to the nature of the work, the appropriate anchorage of the composite is an important element in strengthening with FRCM composites. The use of the anchorage delays the debonding of the composite and thus the better load capacity of the element and the use of the mesh properties is provided.

\section{References}

1. O. Awani, T. El-Maaddawy, N. Ismail, Constr. Build. Mater., 132, 94-111 (2017)

2. L.C. Hollaway, Constr. Build. Mater., 24, 2419-2445 (2010)

3. T. Trapko, Composites Part B, 54, 138-145 (2013)

4. S. El-Gamal, K. Al-Jabri, A. Al-Mahri, S. Al-Mahrouqi, Int. J. Polym. Sci., 2015, 1-10 (2015)

5. Y. Li, X. Liu, M. Wu, Constr. Build. Mater., 134, 424-432 (2017)

6. A. D’Ambrisi, L. Feo, F. Focacci, Composites Part B, 43, 2938-2949 (2012)

7. L. Ombres, Compos. Struct., 109, 294-304 (2014)

8. T. Trapko, Constr. Build. Mater., 73, 332-338 (2014)

9. U. Ebead, Studies on the strengthening of reinforced concrete structures using FRCM, Technical report on progress of Qatar University internal grant projects (Doha, Qatar 2017)

10. F. G. Carozzi, C. Poggi, Composites Part B, 70, 215-230 (2015)

11. T. D’Antino, C. Carloni, L.H. Sneed, C. Pellegrino, Eng. Fract. Mech., 117, 94-111 (2014)

12. L. Ombres, Composites Part B, 69, 418-426 (2015)

13. T. Trapko, D. Urbańska, M. Kamiński, Composites Part B, 80, 63-72 (2015)

14. L. Ombres, Compos. Struct., 12, 316-329 (2015)

15. A. Brückner, R. Ortlepp, M. Curbach, Material and Structures, 41, 407-418 (2008)

16. D. Baggio, K. Soudki, M. Noël, Constr. Build. Mater., 66, 634-644 (2014)

17. E. Tzoura, T.C. Triantafillou, Material and Structures, 49, 17-28 (2016)

18. Z.C. Tetta, L.N. Koutas, D.A. Bournas, Composites Part B, 95, 225-239 (2016)

19. D. Marcinczak, T. Trapko, M. Musiał, Comparison of RC beams strengthened with PBO-FRCM composite with different types of anchorage, fib 2018 Congresss (Melbourne, Australia 2018). 